\title{
La Conquista del desierto y los estudios sobre genocidio. Recorridos, preguntas y debates
}

Fecha de recepción: 5 de septiembre de 2018. Fecha de aceptación: 14 de mayo de 2019
Palabras clave estudios sobre genocidio Conquista del desierto mapuche/tehuelche Nor-patagonia
Pilar Pérez*

\section{Resumen}

El campo de estudios sobre genocidio ha crecido notoriamente en el último cuarto de siglo a nivel internacional. El concepto, usualmente vinculado al nazismo, traspasó las fronteras para proponerse sobre otros procesos históricos permitiendo indagar sobre sus potencialidades y límites. Además, su uso a nivel judicial como coloquial invita a reflexionar sobre el conocimiento no solo jurídico-legal sino socio-político que conlleva. En este trabajo recorremos algunas preguntas centrales de estos estudios para pensar el genocidio indígena y la Conquista del desierto, en particular. Primero, retomaremos el análisis de la Conquista a la luz de la Convención para la Prevención y la Sanción del Delito de Genocidio y sus implicancias, y segundo a partir de la conceptualización de genocidio en las ciencias sociales y humanas. Por último, marcaremos los debates, las provocaciones y los efectos sociales que tiene la aplicación del término genocidio a la Conquista a nivel histórico e historiográfico.

\section{Genocide studies and the Conquest of the Desert. Trajectories, questions and debates}

\section{Abstract}

Key words genocide studies Conquest of the desert Mapuche/Tehuelche North of Patagonia

Genocide Studies have grown notably in the last quarter of a century on an international level. The concept, usually linked to Nazism, has crossed the borders to propose itself over other historical processes allowing to studying their potentials and limits. Moreover, its use at judicial and colloquial levels leads to investigate both, legal and socio-political meanings. In this paper we think about the indigenous genocide and the Conquest of the desert, in particular, focusing on certain questions the studies on genocide have asked. First, we return to the analysis of the Conquest in light of the Convention for the Prevention and Punishment of the Crime of Genocide and its implications, and second we take into account the social and human sciences conceptualization

* Instituto de Investigaciones en Diversidad Cultural y Procesos de Cambio. Consejo Nacional de Investigaciones Científicas y Técnicas (CONICET) - Universidad Nacional de Río Negro (UNRN). San Carlos de Bariloche, Rio Negro, Argentina. E-mail: pperez@unrn.edu.ar 
of genocide. Finally the historical and historiographical debates, provocations and social effects produced by the application of the term genocide to the Conquest are considered.

\section{Introducción}

El concepto genocidio conlleva una enorme diversidad de interpretaciones y supuestos que provienen tanto del sentido común como de las ciencias sociales, humanas y jurídicas. La intención de este trabajo es darle seguimiento a algunas de las muchas preguntas que los llamados estudios sobre genocidio aportan para analizar un proceso complejo que se sintetiza en la ocupación militar de la Nor-Patagonia argentina, conocida como "Conquista del desierto". La diversidad de enfoques, modelos y problemas permiten analizar este complicado y significativo evento histórico, que además tiene implicancias hacia el devenir argentino en el presente. Nos interesa indagar entonces en los problemas y tensiones que provoca el concepto de genocidio, a partir de su renovación teórica, para pensar este proceso. A la inversa, nos proponemos devolver preguntas desde la clasificación de genocidios indígenas hasta el caso histórico específico de la Conquista que enriquezcan el campo de estudios sobre genocidio.

\section{Un recorrido por temas y problemas de los estudios sobre genocidio}

Los estudios sobre genocidio conforman un campo interdisciplinario que está en crecimiento desde principios de la década de 1990 tras la desmonopolización de las investigaciones que los vinculaban casi exclusivamente al nazismo. Esto se debe a la entrada en la escena del debate de nuevos casos históricos entendidos y analizados como genocidios pero con características muy diversas, como los de Armenia, Camboya, Ruanda o Guatemala. Desde la perspectiva legal, el término genocidio fue propuesto por Raphael Lemkin antes de la Segunda Guerra Mundial para juzgar y condenar ataques contra grupos definidos como nacionales, étnicos, raciales o religiosos. La Convención para la Prevención y la Sanción del Delito de Genocidio fue promulgada finalmente por las Naciones Unidas en 1948 -tras un largo debate- como herramienta legal para atender en forma retroactiva los crímenes del nazismo -este fue el conocido caso del SS Otto A. Eichmann en 1962. A su vez, el planteo teórico de Lemkin contemplaba casos ya históricos en su tiempo, como el ataque genocida contra el pueblo armenio (1915) y la experiencia concentracionaria estadounidense sobre sus pueblos originarios en el siglo XIX (Docker, 2008).

Como cualquier herramienta jurídica legal, la Convención tiene potencialidades y limitaciones. Entre otras singularidades, la Convención es una de las pocas normas que condena por crímenes grupales y no individuales, tal y como suele operar el derecho positivo. Sin embargo, no todos los grupos están contemplados en su artículo 2. La ausencia más evidente es sobre los grupos políticos pues, a pesar del largo debate que conllevó el tema, su exclusión no pudo evitarse en la coyuntura de la Guerra Fría cuando la Convención fuera promulgada; pero tampoco fueron incorporados en 1998 cuando se renovó la discusión jurídica frente al Estatuto de Roma. El debate giró en torno al abanico de instancias en las cuales definir al grupo atacado se vuelve, por lo menos, ambiguo e inasible. 
Por otra parte, la definición de genocidio, dada su emergencia en el campo legal, persigue la descripción de hechos y acciones de perpetradores para su procesamiento y eventual condena. Por esto, lo esencial que la norma pretende es probar la intención así como describir y probar los hechos que involucren responsabilidades concretas en un crimen de características imprescriptibles. En este sentido, la Convención delinea algunos parámetros que no pueden ser eludidos en ningún estudio y quizás aquí radica su mayor riqueza.

Desde la perspectiva de las ciencias sociales, partir de un término legal es sin duda sugerente pero a la vez restrictivo para pensar procesos de violencia extrema, complejos y perdurables en el tejido social. Las preguntas e intereses de las disciplinas sociales trascienden los objetivos jurídicos y estudian, por ejemplo, los motivos que llevan al genocidio o a aquellos individuos que, aunque son parte del proceso social, son excluidos en lo jurídico. Estos otros, como pueden ser sectores económicos, testigos, observadores, etc. exceden el marco de lo jurídico pero son centrales para comprender los efectos sociales del genocidio. Por esto, ya a partir de la década de 1980 la sociología y las ciencias políticas encabezaron las preguntas en torno a experiencias genocidas.

Entre otros debates, nos interesa recuperar el que se libró entre los primeros autores que intentaron definir genocidio por fuera -aunque sin denostarla- de la Convención. Aquí podemos mencionar dos vertientes que polarizaron las posiciones. En primer lugar, los estudios que consideran el nazismo como modelo único desde el cual interpretar un genocidio. Es en parte el modelo que sigue Steven Katz (1994) para dar su definición de genocidio, la que obstruye la posibilidad de pensar otros procesos bajo la misma terminología. El nazismo, como cualquier otro caso histórico, tiene rasgos irrepetibles. Katz acotó su definición a estos y, por lo tanto, excluyó la consideración de cualquier otra experiencia como genocida. Uno de los rasgos salientes del nazismo es la existencia de campos de exterminio, verdaderas fábricas de la muerte que inscriben al nazismo en el desarrollo material e ideológico del capitalismo. En el otro extremo, Israel Charny (1991) ofrece una definición tan amplia que prácticamente cualquier acto de violencia en cualquier periodo histórico puede considerarse un genocidio. Charny resalta la capacidad de la Convención respecto de la "prevención" y por esto admite que prefiere equivocarse en la forma de nombrar un proceso de violencia antes que excluir cualquier proceso genocida. Charny elimina inclusive la variable de intención de la definición, así como la contemplación de las coyunturas de guerra. Este autor repara en la apertura de su definición colocándose en un lugar fuertemente militante y consciente de la negación del genocidio como experiencia histórica compartida.

Entre ambos podemos enumerar varios trabajos que, desde las disciplinas mencionadas, buscan definir situaciones en las que existen condiciones que propenderían a un genocidio. Para esto diferentes autores proponen modelos que podemos agrupar en: 1) los regímenes políticos -si son democráticos o autoritarios o en qué estadio de desarrollo burocrático de encuentran, 2) los tipos de sociedades -si son diversificadas u homogéneas- y 3) los grupos identificados como vulnerables ante coyunturas hostiles o de crisis económica -género, raza, diferencias políticas; véanse las clasificaciones propuestas por Fein (1993), Kuper (1981) y Harff, (1988). Claramente estos trabajos buscan desmenuzar con profundidad lo que implican los pasos para llegar a un genocidio. Su motivación está anclada en identificar señales en los comportamientos sociales que nos permitan a los académicos describir indicios para la prevención del delito de genocidio. 
Los modelos así propuestos son muchas veces difíciles de aplicar pero son también cuestionables en sus mismos supuestos ¿Cómo se define un régimen autoritario o democrático?; ¿cómo se plantean las diferencias raciales dentro de una nación?; ¿las diferencias políticas están solo ligadas a la política partidaria o incluyen diferentes formas de hacer política? No obstante, los modelos producidos por estos autores -entre muchos otros que podríamos mencionar- generan debates, preguntas y reflexiones en torno a, por ejemplo: las vinculaciones entre genocidio y guerra -si solo aparecen relacionados o son excluyentes, qué características comparten, si la guerra es producida como discurso para justificar el genocidio-; o bien la constitución de la víctima -si debe ser indefensa para ser considerada como tal o si están autodefinidas o las define el perpetrador-; $y$, finalmente, qué rol juegan los contextos particulares y trayectorias históricas para llegar a una situación de violencia extrema como un genocidio.

Otras perspectivas reflexionan sobre el genocidio en su carácter de manifestación moderna. Estos autores consideran lo moderno en términos weberianos en tanto proceso inscripto en el paso de racionalización y desencantamiento del mundo que tiene su doble eje en el proceso de revolución industrial y división del trabajo social y la consolidación de la administración burocrática en los estados nacionales. Ambos procesos están anclados en el iluminismo y atravesados por la exclusión discursiva "civilización o barbarie". Desde esta matriz, la obra más acabada, que a su vez retoma los planteos de Hanna Arendt sobre el totalitarismo y la banalidad del mal, es el trabajo de Zygmunt Bauman (1989) sobre el Holocausto.

Este filósofo analiza mediante una metáfora botánica lo que define como un "Estado jardinero", ya que mediante un aparato burocrático eximio busca por medio de un genocidio generar un proyecto a futuro que contempla una sociedad diferente, libre de "yuyos", y por ende mejor. La modernidad es la condición de posibilidad del racismo, de la deshumanización y de la burocratización de los medios que son capaces de paralizar a una sociedad y conducirla a ese estadio diferente bajo el amparo del Estado. El tema de la modernidad, o no, se vuelve clave para pensar los procesos de colonización o de incorporación forzada de pueblos originarios a los Estados nacionales -como veremos más adelante.

Las preguntas de los estudios sobre genocidio, entonces, se vuelcan tras estos primeros ejes de debate a enfocar en cinco objetos: la sociedad en su conformación histórica, los perpetradores -características sociológicas, tecnologías de violencia, etc.-, las elites y sus vinculaciones políticas y económicas, las víctimas y las diferentes formas de singularización de las mismas, y finalmente, los observadores y los testigos -aquellos sobre los cuales la violencia no se ejerce en forma directa, que conocen o avalan la violencia.

El planteo teórico sociológico se desprende de la producción de modelos y se introduce en análisis históricos entre los cuales se destaca el trabajo de Christopher Browning en su libro Ordinary Men (1993). Este autor, influenciado por los experimentos del psicólogo Stanley Milgram en la década de 1960, estudia al batallón 101 de la unidad de reserva de la policía alemana durante el nazismo. Su trabajo apunta a entender cómo hombres comunes -conscriptos- se vuelven asesinos en el contexto de un grupo fuertemente jerarquizado, debiendo obediencia y cumpliendo su deber. 
1. La Red es un colectivo de investigadores/as, comunicadores/as, artistas y militantes que se formó en 2005 para reconstruir históricamente el proceso denominado Conquista del desierto y del desierto verde, también para divulgar los resultados de estas investigaciones (Véase Delrio, et al., 2018).

2. Término utilizado por Briones y Delrio (2009) para referir a un evento que condensa diversos significados sobre la construcción de nacionalidad argentina.

3. Algunos autores (Viñas, 1982; Curruhuinca y Roux, 1984) habían retomado estas denuncias en sus trabajos y trazado similitudes entre la última dictadura y la Conquista.

4. No me limito aquí a los trabajos de la Red; existen destacados trabajos sociológicos, antropológicos y lingüísticos que narraron este proceso sin necesariamente pensarlo como un genocidio, especialmente desde la década de 1990 como los de Lucía Golluscio, Claudia Briones, Marisa Malvestitti, Mónica Quijada, Miguel Bartolomé y Martha Bechis, entre otros.
La obra de Browning generó una controversia con el politólogo Daniel Goldhagen (1997) quien cuestionó, entre otras cosas, el carácter de autómatas atribuido a los asesinos. Goldhagen colocó en el centro de su propio argumento el consenso ideológico -el antisemitismo eliminacionista alemán con raíces en el siglo XIX-que compartían, según este autor, todos los alemanes. Al margen de la resolución de este debate, -y de las críticas que ambos estudios generaron- los autores pusieron en un acalorado diálogo -arbitrado en abril de 1996 por el Museo de la Memoria del Holocausto y su Consejo en Nueva York- preguntas en torno a la relación entre estructura e ideología, y entre cultura y dominación, que estimularon el análisis de otros procesos genocidas desde una perspectiva antropológica.

Para citar nuevas investigaciones que se abren para los estudios sobre genocidio desde esta perspectiva mencionaremos los trabajos de Alex Hinton para Camboya (2005) y de Mahmood Mamdani para Ruanda (2002). En el trabajo de Hinton, el antropólogo estudia desde un análisis etnográfico y lingüístico cómo los sentidos de pertenencia y exclusión están en el centro del genocidio, incluso dentro de un sistema que propone la igualdad comunista como fuera la experiencia camboyana. Este caso histórico permite al autor demostrar una ingeniería de marcación de personas -generada discursiva y materialmenteque fuera el motor que permitió reconfigurar social y económicamente un país a partir del sometimiento y la muerte de miles de personas. Mientras el caso de Camboya está centrado en la toma del poder de una elite intelectual que opera a través del aparato de Estado refundado para llevar a cabo el genocidio, el de Ruanda retoma el problema del involucramiento social.

Mamdani (2002) analiza lo que define provocativamente como genocidio "popular". El autor enfoca en aquellos que, victimizados por haber sufrido una opresión histórica desde la misma descolonización de Ruanda -los hutus-, se reconvirtieron en los perpetradores de un genocidio impulsado desde el Estado pero instrumentado por la sociedad. El genocidio en Ruanda se aleja de las tecnologías de guerra y nucleares para volver sobre las herramientas mínimas que posee cualquier campesino ruandés para llevar adelante un "genocidio popular". A fin de articular respuestas sobre este proceso, Mamdani parte del cruce entre geografía -entendiendo la región como móvil e históricamente definida- e historia -las trayectorias que conducen al genocidio-, repolitizando el cuerpo social que muchas veces es congelado en lecturas sobre guerras tribales o conflictos interétnicos, que no son más que formas de racializar las diferencias políticas.

\section{La Convención para la Prevención y Sanción del delito de Genocidio y la Conquista del desierto}

La Convención resultó en nuestra experiencia colectiva -como Red de Investigadores/as en política indígena y genocidio en Argentina- ${ }^{1}$ un disparador para nuestras preguntas para abordar un proceso complejo y epitomizante ${ }^{2}$ como la Conquista del desierto. Aunque la Conquista era ya denunciada como genocidio desde las organizaciones mapuche-tehuelche y de derechos humanos desde la década de $1980,{ }^{3}$ el vacío histórico de investigaciones concretas sobre el derrotero indígena durante y después de las campañas continuaba siendo una pregunta a responder. Si bien aun existen numerosas líneas de trabajo para desarrollar sobre este proceso, el salto de conocimiento producido desde diferentes disciplinas en el último cuarto de siglo es elocuente. ${ }^{4}$ 
La Convención contempla en su artículo 2 que:

Se entiende por genocidio cualquiera de los actos mencionados a continuación, cometidos con la intención de destruir total o parcialmente a un grupo nacional, étnico, racial o religioso como tal:
a) Matanza de miembros del grupo;
b) Atentado grave contra la integridad física o mental de los miembros del grupo;
c) Sometimiento intencional del grupo a condiciones de existencia que hayan de acarrear su destrucción física total o parcial;
d) Medidas destinadas a impedir los nacimientos en el seno del grupo;
e) Traslado forzoso de niños del grupo a otro grupo.
(Convención 2018, artículo 2: 5). ${ }^{5}$

La primera parte de este artículo nos alienta a reflexionar sobre dos cuestiones clave de las campañas militares de ocupación de la pampa y la Patagonia: la intención y la definición del grupo "como tal". Identificar la intención en el crimen de genocidio ha demostrado ser un punto de debate entre quienes lo estudiamos. Difícilmente los perpetradores de estos crímenes dejan pruebas indiscutibles para demostrar la intención -este es un común denominador en diversos casos de genocidio-, por lo menos desde la perspectiva de la prueba jurídica.

Un primer punto a tener en cuenta es que las fuentes utilizadas para la prueba jurídica son valorizadas y jerarquizadas siguiendo cánones habituales de construcción de relatos hegemónicos. En breve, los archivos y la documentación oficial cobran el mayor peso por encima de otro tipo de fuentes y relatos, incluso de reconstrucciones de hechos basados en testimonios de sobrevivientes y registros materiales. La ausencia o existencia de un documento parece torcer la balanza y cerrar el debate. En segundo lugar, la búsqueda por demostrar la intención evidencia lo limitado de la misma como explicación de los efectos sociales de un genocidio, en contraste con los motivos que conducen y legitiman el mismo.

No obstante, para la Conquista del desierto y en relación con las fuentes de la historia existe documentación que demuestra la preparación y organización por parte del sistema de Estado para llevar adelante una avanzada militar que terminara con la "cuestión indígena". Entre ellas, podemos destacar las comunicaciones internas de las fuerzas armadas y los cambios estratégicos para determinar los pactos y tratados de la década de 1870 (De Jong, 2007); los debates dentro del Congreso de la Nación, las expresiones de la elite política a través de la prensa y la exacerbación de la peligrosidad indígena en el mismo periodo (Lenton, 2005); y las políticas de distribución de personas (Mases, 2002).

Además en fuentes de época, como por ejemplo aquellas provenientes de la prensa, de los salesianos, de la memoria social, es habitual encontrar palabras como "exterminio" y relatos de mayor crudeza y claridad por parte de políticos y militares de la época que revelan su intención. A su vez, dentro de las fuentes oficiales se identifican silencios y omisiones en momentos clave entre aquellas fuentes de mayor circulación y exposición -como pueden ser las memorias de los ministerios-. Sin embargo, cuando se indaga en la documentación sostenida de forma interna entre los responsables políticos y los hombres dentro del territorio ocupado se encuentran definiciones concretas

\author{
5. Disponible en Internet: https:// \\ www.un.org/en/genocidepreven- \\ tion/documents/Appeal-Ratifica- \\ tion-Genocide-FactSheet-SP.PDF. \\ (página 5 de 6). Consultado el: 18 de \\ marzo de 2018
}


sobre políticas a seguir, como deportaciones, persecuciones y muerte de grupos concretos (Pérez, 2015).

Pero ¿qué encontramos en la búsqueda de fuentes que demuestren la intención del genocidio? Esta pregunta nos conduce a atravesar archivos, memorias, y registros muy disímiles en donde aparecen identificados múltiples motivos que son constituidos por discursos y hechos que justifican y legitiman la Conquista. Esta búsqueda de la intención nos permite hablar y reflexionar sobre el trasfondo político, económico, social e ideológico del genocidio. Es decir, los motivos de corto y largo plazo que llevan al crimen y que en definitiva nos permiten indagar los consensos y disputas sociales, durante y después de la ocupación militar del territorio.

Los motivos en cualquier proceso legal son excluidos del quehacer jurídico. Sin embargo, son centrales entre los objetivos de las ciencias humanas y sociales. ¿Cómo fue el proceso previo de planificación de la avanzada militar?, ¿qué lugar ocuparon en ésta las tierras y las personas del "desierto"? y también ¿qué repercusiones conllevó hacia adentro del espacio de construcción de una elite -la oligarquía nacional- y de conformación del sistema capitalista y el modelo agro-exportador? y ¿cuál es lugar que se le otorga a lo indígena dentro de la constitución de la comunidad nacional?

Los motivos incluyen también las elaboraciones en torno a la modelación de la Nación, el territorio y el Estado a partir de la Conquista y de la incorporación forzada de la Patagonia y sus pueblos. Esto a su vez nos conduce a observar la sociedad de la época, su inmersión, conocimiento y participación en el devenir de los hechos. A partir de esta búsqueda inicial y la apertura a indagar y contemplar el resto de los motivos concomitantes es que se revela la construcción de una Nación blanca; la consolidación del grupo de poder y la materialización de un proyecto económico en el marco de los debates de la época.

Por su parte, el enfoque sobre el grupo en términos raciales, étnicos, religiosos y nacionales nos conduce a pensar la constitución histórica de ese grupo. Como referíamos previamente, la Convención fue atravesada por el debate de coyuntura respecto a incluir o no los grupos políticos que fueron finalmente excluidos. Dentro de los argumentos de su exclusión está la temporalidad o duración de una adscripción política en contraste con el resto de las pertenencias. Sin embargo, el resto de los grupos que parece fácilmente identificable no lo son tampoco y no lo fueron en los casos en los que se juzgó el crimen de genocidio -como lo expresó el Tribunal Internacional para juzgar el genocidio en Ruanda que encontraba serias dificultades para distinguir étnicamente hutus de tutsis. ¿Quién o cómo se define al grupo? Una definición en sí misma corre el riesgo de esencializar su existencia. Así, la necesidad de reconstrucción histórica de la relación entre victimarios y víctimas es central para entender cómo se producen o recortan estos grupos desde la perspectiva del perpetrador y la sociedad atravesada por la violencia genocida.

En la Conquista, la denominación de los indígenas se vuelve relevante en varios estudios antropológicos, etnohistóricos y geográficos. Podemos mencionar que durante la década del 1870 las fuerzas armadas resolvieron negar el reconocimiento habitual de soberanía y pertenencia nacional en pactos y tratados a los grupos indígenas con quienes dialogaban. Esto significó un anticipo sobre los futuros abandonos deliberados de los acuerdos durante la avanzada militar. Por otra parte, la construcción de un "indio", el indio malonero, para fines de esa década contrasta con la diversidad reconocida en décadas previas de 
pampas, ranqueles, huiliches, araucanos, boroganos, manzaneros, o "gente de" determinados caciques o lugares, entre otros. Este cambio significativo tendió a exotizar y reducir la pertenencia indígena a un estereotipo concentrado en el "indio malonero" =excluido incluso de la cartografía oficial del territorio. Por último, está la construcción política -y más adelante también "científica"- de los "indígenas chilenos" e "indígenas argentinos" sobre los que se adjudicaron hasta el presente adjetivos relativos a la pertenencia nacional impuesta. ${ }^{6}$

En tanto, la segunda parte del artículo 2 de la Convención nos permitió desandar algunas de las acciones que, o bien se desconocían o eran entendidas dentro del marco de una "guerra" revelando, al mismo tiempo, la enorme dificultad de conceptualizarla como tal.

En primer lugar, la avanzada militar del ejército argentino no involucró la confrontación con otros ejércitos. Las fuentes provenientes de las fuerzas de seguridad demuestran que prácticamente no existieron episodios de confrontación. Podemos mencionar, quizás, dos excepciones que son descriptas en las memorias del ministerio de guerra. El combate sobre la cordillera de indígenas que, en fuga, se defendieron de las fuerzas armadas que los perseguían y el llamado "combate de Apeleg", que en su relato revela más un asalto por sorpresa a las tolderías -es decir, a las familias- que un enfrentamiento de algún tipo. En cambio, abundan los relatos de aquellos que murieron en las avanzadas bajo las armas o "entregándose" a situaciones de hambre y frio extremos, en los traslados o marchas de la muerte por cientos de kilómetros (Delrio, 2005; Pérez, 2016).

El otro movimiento estratégico político-militar fue la deportación de miles de hombres, mujeres, niños y niñas hacia diferentes polos de crecimiento económico y ciudades del país. Bajo esta dinámica se desmembraba a las familias indígenas y se obligaba a las y los individuos a formar parte de un mercado forzado de trabajo. Finalmente, y como símbolo crucial para sellar al pasado la "cuestión indígena" la exotización de sus cuerpos -en vida y muertos- devenidos en piezas de museo (Mases, 2002; Pepe et al., 2008).

En tercer lugar, cabe destacar que los desmembramientos familiares y sus fines fueron incluso denunciados dentro del Congreso de la Nación. Primero, estas personas fueron utilizadas como mano de obra forzada. Pero también y dada la masividad de distribución de niños y niñas fue una estrategia que involucró a la sociedad en el proceso civilizatorio. Para esto se pedía a la institución de beneficencia encargada de su distribución que insistieran en el bautismo, cambio de nombre, inculcar valores y creencias religiosas y occidentales. Por otra parte, los proyectos de blanqueamiento a partir de colonias mixtas -entre indígenas e inmigrantes- también pretendían terminar de forma biológica la reproducción de su sociedad y su cultura.

En cuarto lugar, la instalación dentro y fuera del territorio patagónico de campos de concentración administrados por las fuerzas de seguridad desde el inicio de la Conquista hasta varios años después de concluidas oficialmente las mismas. Los campos de concentración funcionaron en diversos tamaños y tiempos albergando a los indígenas reducidos, ya fueran los sometidos en las avanzadas de las columnas militares o aquellos que se presentaban voluntariamente. Los indígenas presos en los campos eran de todas las edades y género y estaban recluidos allí por ser "indios" y no por ningún crimen cometido (Papazian y Nagy, 2010). Desde los campos se efectuaban las deportaciones indistintamente de cómo fueran concebidos -sometidos o presentados- o de
6. Al respecto, Briones y Carrasco (2000), Delrio (2002), De Jong (2007), Lois (2007) y Rodríguez (2010), entre otros. 
su pertenencia étnica -mapuche o tehuelche-, todos sufrían la misma incertidumbre y desenlace.

El trabajo de reconstruir históricamente la Conquista del desierto permitió conocer el devenir indígena durante la misma. Las prácticas aquí enumeradas expresan una vinculación entre el artículo 2 de la Convención y la experiencia histórica. Es decir, que las denuncias que comenzaron como un planteo político cobran una relevancia histórica que nos invita a profundizar en la pertinencia del concepto de genocidio en diálogo tanto con otros conceptos como con otras experiencias históricas.

\section{El análisis histórico y los estudios comparativos sobre genocidios}

Los estudios sobre genocidio han producido una cantidad significativa de modelos para pensar procesos históricos y, en menor medida, -aunque es una crítica que han asumido y se encuentra en vías de revertirse- aportes históricos para pensar el crimen de genocidio y sus efectos. Por esto nos centraremos en pensar al genocidio en tanto proceso histórico, tomando en cuenta su periodización así como el régimen de historicidad. Paralelamente el desarrollo históricamente situado permite e impulsa estudios que vuelven relevantes preguntas en torno a las formas de entender al Estado y la sociedad. Estos complejizan las zonas grises (Levi, 2005) de los grupos discretamente identificados ya sea como víctimas, perpetradores y también la constitución de ideologías y discursos hegemónicos.

El genocidio es entendido como un fenómeno complejo de múltiples capas de análisis (Straus, 2006). Por esto, un punto de convergencia, en especial entre los estudios comparativos sobre genocidio, se resume en analizar el proceso en sus diferentes etapas. La mayoría de los trabajos que recuperan esta perspectiva suponen de mínima una periodización tripartita: los pasos que conducen a la violencia abierta; la violencia genocida en sí misma y el período de negación. Algunos autores incluso desagregan estas etapas caracterizándolas en momentos o pasos hacia el genocidio y después. A modo de ejemplo, Stanton (1998) identifica ocho momentos con un eje articulador en el tratamiento de la víctima: clasificación, simbolización, deshumanización, organización, polarización, preparación, exterminio y negación. Por su parte, Feierstein (2007) distingue seis etapas: la construcción de una otredad negativa, el hostigamiento, el aislamiento, el debilitamiento sistemático, el aniquilamiento material y la realización simbólica. De esta forma, considerando el proceso en tres etapas y desgranando cada una de ellas -la marcación de la víctima, la violencia abierta y los efectos de la misma- se puede nuclear una creciente producción de artículos y libros que retoman diferentes casos.

En general, los estudios que abordan la etapa de marcación de la víctima enfocan en la intención, las construcciones de alteridad y la atribución de peligrosidad a esos otros internos o externos, la consolidación de un pensamiento y grupo hegemónico, las ideologías imperantes y las coyunturas socioeconómicas particulares que habilitan y viabilizan el desencadenamiento de la violencia (Mandami, 2002; Hinton, 2005). El periodo de desencadenamiento de la violencia es estudiado a través de indagar en los dispositivos y técnicas de los perpetradores, así como las estrategias de resistencia y agencias si las hubiere. Particularmente, como se destaca en los estudios sobre violencia (Schepers-Huges \& Bourgois, 2006), este tipo de experiencias son prácticas 
transformadoras que generan nuevas subjetividades (Feldman, 1991), más allá de las propias características históricas con las que se llega al genocidio. Una introducción de preguntas desafiantes gira en torno a la sociedad en general durante el genocidio y también sobre aquellos que son considerados "testigos" u "observadores". Estos sujetos muchas veces cumplen roles poco claros, o contradictorios, a veces cooperando por decisión u omisión con el perpetrador y otras garantizando supervivencias de personas y memorias.

Finalmente, el periodo de negación es el que permite entender el proceso en su totalidad y es clave para la inteligibilidad de la situación, su eventual procesamiento y condena. Principalmente es un periodo signado por silencios -de distinto orden y por diferentes causas- que llamativamente solo quiebran los sobrevivientes (Smith, 1991). La etapa de negación o de realización simbólica es la que sella el pacto de silencio en los diferentes niveles sociales, marca el límite entre lo contable o decible y aquello que es secreto. Este periodo interrumpe el proceso continuo de la historia -como producción y narrativa- y está marcado por aquello que se oculta, se niega y se convierte en un impensable o un proceso natural del progreso.

Partir del proceso histórico para pensar el genocidio resulta central para la Conquista del desierto en tanto el periodo de realización simbólica estuvo marcado por un extendido silencio de más de un siglo y ausencia de cuestionamiento -fundamentalmente académico y educativo- a la versión de la "guerra" de Conquista. Por esto, en la Argentina el debate sobre genocidio indígena y su negación forma parte de un debate contemporáneo, un debate del siglo XXI (Navarro Floria, 2006). Lo que se pone en cuestión es, entre otros temas, la cuantificación de muertos, supuestas razones naturales que conllevan los procesos de evolución, la mentalidad de la época, eventuales abusos sin intención, la ausencia de una política sistemática de exterminio, la guerra que fue perdida, por mencionar algunos. No obstante, la negación implica un opuesto al cual remitir y discutir, argumentar, contra-argumentar y militar. Sin embargo, desde nuestra perspectiva, la negación habilita un espacio político a la duda. En cambio, el silencio, si bien podría considerarse una forma de negación, implica un vacío. Este vacío afecta de forma particular a la sociedad mapuche y tehuelche pero también al colectivo de la sociedad argentina, como veremos.

Tras más de un siglo de silencio, en los últimos años nos encontramos con la negación como espacio de disputa social y también entre los historiadores. Ciertos historiadores militares, como Ruiz Moreno (2009), buscan nuevamente reivindicar el rol civilizador de las fuerzas armadas dentro de una coyuntura de renovada disputa social en torno a las fuerzas de seguridad y de la Conquista, en particular. Otros investigadores sostienen la lectura de larga duración de la "guerra" reproduciendo la ficción de paridad de condiciones y recuperando el marco conceptual instalado por los propios perpetradores (Escolar, et al., 2015). ${ }^{7}$ Mientras algunos directamente impugnan la versión del genocidio aludiendo a la agencia indígena y su lugar de resistencia desde donde justifican la violencia estatal por sobre familias y el fracaso indígena (Sabina, 2016). ${ }^{8}$

Finalmente la negación desde el sentido común, un sentido común manufacturado por la narrativa celebratoria de la Conquista del desierto como avance final de la civilización sobre la barbarie que se encuentra naturalizado en manuales educativos, monumentos, nombres de pueblos y calles y efemérides de mínimo. Al presente, y luego de los episodios ilegales de violencia sobre comunidades mapuche durante el 2017 por parte de las fuerzas de seguridad
7. Véase el trabajo de Walter Delrio publicado en este Dossier.

8. Según Sabina (2016: 374): “Avellaneda prácticamente duplicó el territorio nacional y pacificó la frontera a través de la denostada Conquista del Desierto, uno de los episodios más polémicos de nuestro pasado. Sobre esta etapa no ayudan los análisis en boga, que constituyen verdaderos absurdos historiográficos observando con ojos del presente acciones del pasado". Más adelante afirma que si la Conquista fue una guerra y los indígenas perdieron no cabe ahora reclamar por fracasos del pasado. Su análisis sigue la línea de Ruiz Moreno (2009), citado anteriormente. 
9. Trouillot (1995) destaca que son justamente los trazos provenientes del pasado los que impiden que la historia como narrativa se piense como una mera ficción. Para el autor los eventos dejan trazos que pueden volverse hechos, y la materialidad de los mismos circunscribe las narrativas de futuros posibles. del Estado, la prensa y las opiniones en general vertidas en redes sociales dan cuenta de la profundidad del discurso de la guerra ganada al salvaje del desierto en el presente y al negacionismo instalado en la sociedad argentina. Si nos retiramos por un momento del debate conceptual -guerra, Conquista, asimilación, genocidio, etc.- y sus implicancias, debemos resaltar que los hechos recuperados por el trabajo en múltiples investigaciones -lingüísticas, antropológicas, históricas, sociológicas, geográficas, de crítica literaria, etc.- en lo que va del siglo XXI obliga a pensar una nueva narrativa histórica nacional así como a darle sentido a trazos del pasado que no fueron contemplados en los discursos hegemónicos. ${ }^{9}$

Ocurre que si bien existieron relatos contemporáneos en el siglo XIX de lo que sucedía y voces que denunciaron el proceso de Conquista, no fueron incorporadas a la narrativa oficial. Las versiones que contaban qué pasó con los vencidos -nos referimos aquí a las indígenas, aunque no fueron las únicas que lo relataron- quedaron estalladas, desgajadas, deshistorizadas y despolitizadas. Paralelamente se consolidó y divulgó una narrativa nacional en la que otras historias o trazos de la misma fueron vedadas, sin posibilidad de anclaje en el continumm de la historia hegemónica y, por lo tanto, la Conquista como genocidio se volvió un impensable de la historia (Trouillot, 1995).

En este sentido, el régimen de historicidad aceptable -y fomentado por el Estado y sus discursos legitimadores- es el que inscribe el progreso desde el presente hacia el futuro, comprobable a través de la consolidación y evolución de las instituciones estatales (Hartog, 2007). Desde esta perspectiva, el pasado es solo interrogado para justificar este presente, aquello que lo disturba implica al mismo tiempo alejarse del futuro deseado. Ahora este pasado introduce una enorme cantidad de hechos, documentos, memorias, en la parte silenciada del proceso que necesariamente altera el pasado y la relación entre pasado y presente e ilumina la posibilidad de pensar otros devenires posibles.

Este debate sobre la historia y sus narrativas lo es también sobre el EstadoNación-Territorio argentino que se consolida en y a través de este proceso histórico. Desde la perspectiva político-económica se consolida un grupo de poder con propiedades y socios comerciales que perduran a lo largo del siglo $\mathrm{XX}$, por lo menos. Configuran una distribución particular de la tierra y su concentración en manos privadas, a la vez que instalan prácticas de pertenencia/ exclusión ejecutadas por políticas estatales desde entonces para definir los pobladores legítimos de ese territorio ahora argentino y los márgenes.

En el plano de la indagación académica también desafía las múltiples y contrastantes concepciones de Estado que manejamos para pensar este mismo proceso. Los estudios sobre genocidio nos permiten indagar también en este punto ya que abren preguntas vinculadas al Estado como único perpetrador del crimen $\mathrm{y}$, a la vez, colocan en escena a la sociedad en su conjunto. Maybury-Lewis (2002) propone leer los genocidios o masacres genocidas sobre los pueblos indígenas en estrecha vinculación con la conformación del Estado-Nación y sus grupos étnicos internos, una relación conflictiva y de mutua determinación que sustancia la discursividad en torno a la idea del estado en peligro. Sin embargo, el autor no demoniza al Estado, ni le resta responsabilidad sino que entiende que la coyuntura finisecular y la emergencia de las minorías dentro del Estado durante la década de 1990 fracturaron -o distanciaron el guión- entre Estado y Nación, y por esto las posibilidades de repensarlo se enriquecen. En este sentido, Maybury-Lewis (2002) insiste en la necesidad de repensar el Estado en su dialéctica con sus otros internos. 


\section{Cuando el genocidio es perpetrado sobre indígenas}

Una idea habitual en los estudios de genocidio es que es un viejo crimen con nombre nuevo (Kuper, 1981). Así, se abre al abanico histórico la propuesta de pensar otros procesos muy antiguos como genocidas; por ejemplo, la destrucción de Cartago en el siglo III por parte de Roma, las conquistas mongolas del siglo XIII y la caza de brujas en Escocia en el siglo XVI (Chalk y Jonassohn, 2010). Sin embargo, la mayoría de las y los autoras/es acuerda en distinguir los genocidios perpetrados antes de la consolidación de Estados Nacionales y los que son llevados a cabo bajo un estado-nación que se vuelve sobre sus otros internos o externos -en los casos coloniales.

Los genocidios perpetrados sobre pueblos indígenas parecen quedar en el vértice entre una y otra distinción. Muchas veces son considerados de antemano como genocidios pre-modernos; incluso se explican estos genocidios como perpetrados por parte de agencias no estatales, como colonos o individuos que defienden sus intereses económicos particulares.

En esta operación se corre el riesgo de seguir una clásica operatoria por parte de los Estados Nacionales ya identificada por Alonso (1994) de: 1) relegar lo indígena al pasado y 2) asumir una guerra contra un otro externo. Esta autora sostiene que la etnicidad es parte de lo que llama "efectos particularizadores de la formación del Estado"; es decir, y retomando el planteo sobre la definición del grupo, que los Estados modernos generan un plan totalizador que es la constitución de una Nación y un territorio. Este plan tiene pretensiones homogeneizadoras que buscan identificar y definir pueblo/territorio/Estado pero también los otros internos. Estos efectos producen diferenciaciones jerarquizadas de los habitantes de la Nación. Así, la etnicidad, como la clase, el género, la orientación sexual, o la edad, es central para la construcción de estatus y de poder dentro de las sociedades estatales.

Esta doble operación -de arrojar al pasado y volverlo otro externo- opera en nuestro caso para excluir a los mapuche y tehuelche del grueso del relato histórico del siglo XIX y al mismo tiempo borrarlos del devenir pos-Conquista. Los indígenas no solo son identificados bajo un estereotipo de "indio malonero", que deshistoriza las relaciones antiguas entre diferentes grupos y los múltiples Estados desde la colonia hasta los Estados modernos sino que los arranca del devenir histórico alojándolos en un pasado pero sin tiempo. Tal y como venimos desarrollando esta operación, discursiva en principio pero poderosa para generar diferencias sociales, es la que permitió que en el proceso de incorporación forzada al Estado-Nación argentino los indígenas fueran incorporados como ciudadanos de segunda en la legislación y en las prácticas, hábitos y costumbres llevadas adelante por la burocracia estatal. Esta incorporación subalterna es el resultado del genocidio y su silenciamiento es parte constituyente del éxito del proceso.

Paralelamente emergen desde el debate teórico las clasificaciones como etnocidio, culturicidio o limpieza étnica. Según los casos seguidos por Totten, et al. (2002), se suele avalar estas categorías para expresar la supresión física involuntaria, por ejemplo, o la mortandad de indígenas por viruela en el contexto de la Conquista de América. Al mismo tiempo se utiliza etnocidio para procesos de asimilación forzada con la intención de "civilizar" o re-educar como suele caracterizarse el caso de las escuelas residenciales en Canadá. De nuevo, estas clasificaciones funcionan como atenuantes (Delrio, 2010) ya que parten de los supuestos sobre el grupo de víctimas: ¿son disociables las 
personas de su cultura?, ¿reviste alguna particularidad identificar de antemano que este es un grupo étnico?

Así, tomar el término etnocidio en aras de una supuesta rigurosidad atribuida a lo indígena implica en lo inmediato: 1) minimizar la matanza física o colocarla en un plano secundario respecto del ataque producido sobre una cultura, 2) colocarla en el lugar de un daño colateral -o carente de intención y motivos-, 3) reafirmar lo inevitable del proceso, naturalizarlo o minimizando los largos debates dentro del estado y 4) abonar la idea de la asimilación forzada o "inevitable" en el marco de la modernización y el desarrollo del capitalismo. Por esto, recuperamos la dimensión conceptual de genocidio.

Pensar la Conquista como un genocidio implica dimensionar tanto la manufacturación de ese 'otro interno' -eventualmente peligroso-, tanto como la real desproporción de la violencia efectuada durante la ocupación militar y los efectos por sobre la sociedad indígena y argentina a posteriori -que retomaremos en el próximo acápite. Sin embargo, llegado este punto nos resulta válida la pregunta en torno a la victimización o des-agenciamiento de los indígenas. Desde nuestra perspectiva, lejos de implicar la falta de agencia o resistencia por parte de las víctimas se contemplan, analizan y reconstruyen una variedad de acciones que permiten entender la existencia, al presente, de comunidades, familias, personas que se reconocen como mapuche y/o tehuelche en el sur argentino.

Más bien se jerarquiza y contempla desde la posibilidad más íntima de conservar la memoria social, hasta las fugas, pasando por formas de organización política y social que lograron perdurar pese a la desproporcionada asimetría de relaciones de poder y el ejercicio de la violencia simbólica y material de forma persistente en su contra. Enmarcar la agencia o resistencia bajo el lenguaje típico y limitado de la "guerra" reduce sensiblemente nuestras posibilidades de dimensionar, registrar y comprender las movilidades estructuradas (Grossberg, 1992) de los indígenas del sur. Por el contrario, habilita ese mismo lenguaje estigmatizando decisiones familiares y políticas difíciles en "traiciones", "colaboraciones" o "cooptaciones" nuevamente despolitizando la agencia indígena. Por esto, rechazamos los términos conceptuales de la guerra como marco para entender la Conquista.

\section{El genocidio como evento creativo, como evento estructurante}

Los estudios sobre genocidio nos permiten enfocar con énfasis en el periodo de realización simbólica o, más específicamente, en su silenciamiento. Pensar los motivos que conducen al mismo refieren más al devenir de esa sociedad y Estado que comienza o se reformula a partir de la marcación y pretensión de eliminación de ese 'otro interno'. La Conquista del desierto constituye un genocidio que fue exitoso por más de un siglo en instalar tanto la versión de la guerra ganada a la "barbarie" y el "desierto" como en clausurar las preguntas en torno a los sobrevivientes de este evento. La llamada "cuestión indígena" fue barrida de la arena nacional aun cuando el problema de los sobrevivientes no estaba resuelto en los Territorios Nacionales del Sur -creados en 1884- y aun cuando el Estado argentino recién comenzaba las campañas militares sobre el norte del país, en un proceso que se extendió oficialmente entre 1884 y 1917.

¿Qué sucedió con los mapuche y tehuelche después de la ocupación militar?; ¿qué sucedió con los sobrevivientes dentro del territorio cuando liberaron los 
campos de concentración? Los indígenas continuaron siendo la excepción dentro de la construcción hegemónica normativizante. Los "indios" representan un 'otro interno' determinado por el biopoder -en términos foucaultianos- ya sea como mano de obra forzada, como trofeo o como preso sin ninguna condena. En definitiva, como un cuerpo disponible y potencialmente asesinable. El "indio" constituye los dos extremos del estado de excepción, en los términos de Agamben (1998), el "hombre lobo" pero también el soberano. ${ }^{10}$ La normalización histórica de la excepcionalidad indígena encarna en los supuestos que se configuran sobre los cuerpos indígenas y las prácticas que sobre estos se habilitan.

Por esto entendemos, siguiendo a Moses (2000) y Wolfe (2006), que el genocidio -en nuestro caso la Conquista del desierto- se vuelve no solo un hecho violento pero aislado sino un evento que estructura las relaciones sociales desde ahí en adelante. Tal y como lo proponen estos autores para el caso australiano, la violencia intrínseca a la ocupación del territorio generó la presunción de que los colonos -los foráneos, inmigrantes o recién llegados de la mano de las políticas estatales- tenían derechos prioritarios sobre la tierra.

Para que triunfe el proyecto de colonización existió una lógica de la eliminación que constreñía y habilitaba las decisiones y prácticas particulares de los colonos como individuos. El Poder Ejecutivo Nacional fue central en la organización y administración de la tierra y el territorio generando, por un lado, enormes concesiones de tierras a compañías y casas comerciales, favoreciendo la extranjerización y concentración de la tierra desde fines del siglo XIX. Por el otro, alentó y priorizó al poblador inmigrante, el pionero, por encima y en detrimento de los sobrevivientes del proceso genocida. Las relaciones sociales se estructuraron en base a esta lógica de extinción -pasada o siempre inminente- de los indígenas. A su vez, el desarrollo de las relaciones capitalistas también se benefició de esta relación estructural de sometimiento que comienza con la ocupación militar y continúa en un proceso de alienación indígena (Pérez, 2017).

Este genocidio "exitoso" se relató en la ausencia y el silencio de los derroteros indígenas en directa oposición con la construcción de los inmigrantes y "pioneros" progresistas que, con su esfuerzo y dedicación según sus propios discursos y los de reconocimiento estatal, fueron quienes finalmente concretaron el desarrollo de la civilización en la Patagonia. Esta versión relatada en numerosas historias pueblerinas del interior de la Nor-Patagonia prioriza las lecturas liberales de hombres que logran mejorar. Sin minimizar el esfuerzo de estas personas y familias, este relato oculta al mismo tiempo las políticas de Estado -fundamentalmente aquellas vinculadas a las tierras y la seguridad de los territorios- que fueron clave para la estratificación jerarquizada de la sociedad patagónica. Si bien algunos sectores fueron marcados y perseguidos de forma intermitente a lo largo del siglo XX -los gitanos, los trabajadores, los anarquistas, etc.- solo los indígenas perduraron en esta marcación de diferencia de forma constante e identificable en la larga duración. ${ }^{11}$

Por esto entendemos también al genocidio como un evento creativo que produjo y naturalizó relaciones de subordinación y dominación sobre un sector invisibilizado de la sociedad argentina. El racismo que atraviesa y constituye estas relaciones es habitualmente negado a nivel social e incluso académico. Sin recaer en las habituales miradas racistas y extranjerizantes sobre los mapuche, muchas veces se soslaya la pertenencia indígena en relación a la clase social
10. Retomando una de las metáforas de Agamben (1998), el indio encarna la figura literaria del "hombre-lobo". Su esencia, reificada por el estado, contiene la latencia de que puede volverse sobre su estado animal y de esta forma ser agente de la disolución de la civilización. Por esto, puede despertar eventualmente reclamos "humanitarios" pero, al mismo tiempo, no puede dejar de ser vigilado.

11. En el presente sobre estos estigmas y estereotipos se montan todo tipo de versiones falaces de terrorismo adjudicado a los mapuche, en particular. 
a la que el grueso de los mapuche y tehuelche pertenecen. En esto también el genocidio demuestra ser exitoso al presente.

\section{La pregunta sobre la reparación}

En este trabajo nos hemos detenido en pensar algunos de los debates que surgen de los estudios sobre genocidio. En primer lugar, a partir de la conceptualización jurídica y de los alcances que la Convención tiene para reflexionar sobre la Conquista del desierto. Al mismo tiempo, las preguntas y temas que se han ido desarrollando a nivel internacional se vuelven centrales para entender la temporalidad del proceso argentino, como sus efectos de corto y largo plazo sobre la población indígena así como sobre el conjunto de la sociedad argentina.

A su vez, el mismo proceso histórico que dimensiona la constitución del estadonación-territorio argentino permite cuestionar la particularización que en los estudios sobre genocidio se hace cuando las víctimas son indígenas. En principio, descartamos el análisis con términos como etnocidio o culturicidio que solo refuerzan la construcción de externalidad producida desde el Estado. En segundo lugar, cuestionamos la idea de un caso pre-moderno cuando justamente es en la Conquista del desierto que el Estado argentino logra constituirse y narrarse y producir sentidos de pertenencia por sobre su población.

Por su parte hemos destacado cómo la visibilidad, que la denuncia social primero y luego la reconstrucción del proceso histórico, ha dado a la temática la convierte en una arena de disputa en donde emerge la negación como práctica política. De este repaso por las preguntas y debates que los estudios sobre genocidio habilitaron para indagar en la Conquista del desierto, nos referiremos a una pregunta latente que tiene que ver con la reparación del crimen de genocidio.

A lo largo del texto nos hemos referido a la construcción de un estereotipo respecto de lo indígena, impuesto principalmente desde la política del siglo XIX y la academia que intenta recortar el objeto de estudio. Esta construcción del 'otro interno' ha perdurado a través del estereotipo del "indio malonero" que, a su vez, es un personaje del pasado pero sin tiempo histórico real. Los motivos que condujeron a un genocidio son tanto de corto plazo -en relación al desarrollo de un mercado de tierras y brazos para el capitalismo del modelo agro-exportador-, como funcionales a la constitución de un territorio nacional libre de "indios" y de una comunidad nacional en vías de civilización y "blanquamiento", construcción hegemónica de largo alcance.

Así cobra especial atención la relación construida entre el Estado perpetrador, la sociedad argentina y las víctimas del genocidio. Si entendemos este proceso en términos históricos entonces podremos imaginar las salidas que aventuren una reparación. Los hechos de la historia -o trazos según Trouillot (1995)- no nos permiten volver el tiempo atrás pero sí identificar la configuración de relaciones sociales a partir del genocidio como evento estructurante. Nos encontramos aun en la etapa de reconstrucción de un evento silenciado y profundamente naturalizado en la sociedad argentina. Así como la pregunta en torno al genocidio provino de la presión social, también los términos de la reparación serán demandados e imaginados desde diversas agencias. 


\section{Q Bibliografía}

" Agamben, G. (1998). Homo Sacer: Sovereign power and bare Life. Stanford, Stanford University Press.

"Alonso, A. (1994). The Politics of Space, Time and Substance: State Formation, Nationalism, and Ethnicity. Annual Review of Anthropology 23: 379-405.

» Bauman, Z. (1989). Modernity and the Holocaust. New York, Cornell University Press.

»Briones, C. y M. Carrasco (200o). Pacta Sunt Servanda. Capitulaciones, Conveniosy Tratados con Indígenas en Pampa y Patagonia (Argentina 1742-1878): documento 29. Buenos Aires, Iwgia. Disponible en Internet: https://www.iwgia.org/es/recursos/publicaciones/317libros/2872-pacta-sunt-servanda-capitulaciones-convenios-y-tratados-con-indgenasen-pampa-y-patagonia-argentina-1742-1878. Consultado el: 18 de septiembre de 2017.

»Briones, C. y W. Delrio (2009). "The 'Conquest of the Desert' as trope and enactment of Argentina's Manifest Destiny" en Maybury-Lewis, D.; Mac Donald, T. \& B. MayburyLewis (eds.), Manifest Destinies and Indigenous Peoples: 51-84. Cambridge, USA, Harvard University Press.

» Browning, C. (1993). Ordinary Men: Reserve Police Battalion 101 and the Final Solution in Poland. New York, Perennial.

»Curruhuinca C. y L. Roux (1984). Las matanzas del Neuquén. Buenos Aires, Plus Ultra.

»Chalk, F. y K. Jonassohn ([1990] 2010). Historia y sociología del Genocidio. Análisis de estudio de casos. Buenos Aires, Eduntref/ Prometeo Libros.

"Charny, I. W. (ed.) (1991). Genocide: A Critical Bibliographic Review. New York, Factson File.

» De Jong, Ingrid (2007). “Acuerdos y desacuerdos: política estatal e indígena en la frontera bonaerense (1856-1866)" en Mandrini, R.; Escobar Ohmstede A.; y S. Ortelli (eds.), Sociedades en movimiento. Los pueblos indígenas de América Latina en el siglo XIX: 47-62. Tandil, IEHS.

»Delrio, W. (2002). “Indios amigos, salvajes o argentinos. Procesos de construcción de categorías sociales en la incorporación de los pueblos originarios al Estado-Nación (1870-1885)" en Nacuzzi, L. (comp.), Funcionarios, diplomáticos, guerreros. Miradas hacia el otro en las fronteras de Pampa y Patagonia: 203-245. Buenos Aires, Sociedad Argentina de Antropología.

"Delrio, Walter (2005). Memorias de expropiación. Sometimiento e incorporación indígena en la Patagonia (1872-1943). Buenos Aires, Editorial de la Universidad Nacional de Quilmes.

"Delrio, W. (2010). Del no-evento al genocidio. Pueblos originarios y políticas de estado en Argentina. Eadem Utraque Europa 6 (10-11): 219-254. Buenos Aires, UNSAM-Miño y Dávila.

" Delrio, W, Escolar, D., Lenton, D. y M. Malvestitti (2018). En el país de Nomeacuerdo. Archivos y memorias del genocidio del estado argentino sobre los pueblos originarios 18701950. Viedma, Ed UNRN.

"Docker, J. (2008). “Are settler-colonies inherently genocidal? Re-reading Lemkin” en Moses, D., Empire, Colony, Genocide. Conquest, occupation, and subaltern resistance in World history: cap. 3. New York, Berghahn Books.

»Escolar, D., Vezub, J. y C. Salomón Tarquini (2015). La “Campaña del Desierto” (1870- 
1890): notas para una crítica historiográfica en Lorenz, F. (comp.), Guerras de la historia argentina: 223-247. Buenos Aires, Ariel.

» Fein, H. (1993). Genocide: A Sociological Perspective. London, Sage.

»Feierstein, D. (2007). El genocidio como práctica social. Entre el nazismo y la experiencia argentina. Buenos Aires, Fondo de Cultura Económica.

» Feldman, A. (1991) Formations of Violence: The Narrative of the Body and Political Terror in Northern Ireland. Chicago, Chicago University Press.

» Goldhagen, D. (1997). Hitler's Willing Executioners: Ordinary Germans and the Holocaust. New York, Vintage.

» Grossberg, L. (1992). We gotta get out of this place. Popular Conservatism and Postmodern culture. Nueva York y Londres, Routledge.

» Harff, B. (1988). "State Perpetrators of Mass Political Murder since 1945" ponencia presentada en la Conference of State Organized Terror: The Case of Violent Internal Repression, Michigan State University. East Lansing, MI, 2 al 5 de noviembre.

» Hartog F. (2007). Regímenes de historicidad. Presentismo y experiencias del tiempo. México, Universidad Iberoamericana.

" Hinton, A. (2005). Why Did They Kill: Cambodia In the Shadow of Genocide. Berkeley, University of California Press.

" Katz, S. (1994). The Holocaust in Historical Context, Vol. 1: The Holocaust and Mass Death before the Modern Age. New York, Oxford University Press.

» Kuper, L. (1981). Genocide: Its Political Use in the Twentieth Century. Harmondsworth, Penguin.

» Lenton D. (2005). De centauros a protegidos. La construcción del sujeto de la política indigenista argentina desde los debates parlamentarios (1880-1970). Tesis Doctoral. Buenos Aires, Facultad de Filosofía y Letras, Universidad de Buenos Aires. Disponible en Internet: http://repositorio.filo.uba.ar/handle/filodigital/1268. Consultado el: 18 de septiembre de 2017

»Levi, P. (2005). Si esto es un hombre. Barcelona, Muchnik Editores.

»Lois, C. (2007). “La Patagonia en el mapa de la Argentina Moderna. Política y "deseo territorial' en la cartografía oficial Argentina en la segunda mitad del siglo XIX” en Navarro Floria, P. (coord.), Paisajes del Progreso. La resignificación de la Patagonia Norte. 1880-1916: 107-135. Neuquén, Editorial de la Universidad de Comahue/ CEP.

" Mandani, M. (2002). When victims become killers: colonialism, Nativism, and the Genocide in Rwanda. Princeton, Princeton University Press.

» Mases E. (2002). Estado y cuestión indígena. El destino final de los indios sometidos en el sur del territorio (1878-1910). Buenos Aires, Prometeo Libros.

» Maybury-Lewis, D. (2002). “Genocide against indigenous peoples” en Hinton, A. (ed.), Annihilating difference. The anthropology of genocide: 43-53. Berkeley/ Los Angeles/ London, University of California Press.

» Moses, D. (2000). An antipodean Genocide? The origins of the genocidal moment in the colonization of Australia. Journal of Genocide Research 2 (1): 89-106.

» Navarro Floria, P. (2006). “El debate historiográfico sobre la conquista de la Patagonia en el contexto de la democracia argentina post-dictadura” ponencia presentada en las II Jornadas de Historia de la Patagonia. Centro de Estudios Patagónicos (CEP), Universidad nacional del Comahue, Gral Roca. 2 al 4 de noviembre. 
»Papazian A. y M. Nagy (2010). Prácticas de disciplinamiento indígena en la Isla Martín García hacia fines del siglo XIX. Revista Tefros 8 (1 y 2): s/n. Disponible en Internet: http:// tefros.blogspot.com.ar/. Consultado el: 18 de septiembre de 2017

»Pepe, F. M. Añón Suárez M. y P. Harrison (2008). Grupo Universitario de Investigación en Antropología Social (GUIAS). Identificación y restitutción. Colección de restos humanos en el Museo de La Plata. La Plata, GUIAS.

» Pérez P. (2015). Futuros y fuentes. Futuros y fuentes: las listas de indígenas presos en el campo de concentración de Valcheta, Río Negro (1887). Nuevo Mundo Mundos Nuevos. DisponibleenInternet:https://journals.openedition.org/nuevomundo/68751\#quotation. Consultado el: 18 de septiembre de 2017

»Pérez P. (2016). Archivos del silencio. Estado, indígenas y violencia en Patagonia Central 1878-1941. Buenos Aires, Prometeo Libro.

»Pérez P. (2017). Sobre la alienación “indígena” para estudiar el desarrollo del capitalismo en el Territorio Nacional de Río Negro (1880-1950s). PIMSA. Documentos y Comunicaciones. Disponible en Internet:-http://www.pimsa.secyt.gov.ar/novedades/ Sobre_la_alienacion_indigena_para_estudiar_el_desarrollo_del_capitalismo.pdf. Consultado el: 18 de agosto de 2018

» Rodríguez M. (2010). De la “extinción” a la autoafirmación: Procesos de visibilización de la comunidad tehuelche Camusu Aike (provincia de Santa Cruz, Argentina). Disertación para obtener el título de Doctor of Philosophy in Literature and Cultural Studies. Washington D. C., Faculty of the Graduate School of Arts and Sciences, Georgetown University.

» Ruiz Moreno, I. (2009). Campañas militares argentinas 1870-1884. La política y la guerra contra indios sediciosos, tomo V. Buenos Aires, Editorial Claridad.

»Sabina, L. (2016). Héroes y Villanos. Buenos Aires, Sudamericana.

» Scheper-Hughes, N. \& P. Bourgois (eds.) (2006). Violence in War and Peace. Singapur, Blackwell.

» Smith, R. W (1991). “Denial of the Armenian Genocide” en Charny. I. (ed.), Genocide: A Critical Bibliographic Review: 63-85. New York, Facts On File,

»Stanton, G. (1998). Eight Stages of Genocide. Genocide Watch. The International alliance to end Genocide. Disponible en Internet: http://www.genocidewatch.org/ aboutgenocide/8stagesofgenocide.html. Consultado el: 18 de septiembre de 2017

»Straus S. (2006). The Order of Genocide: Race, Power, and War in Rwanda. Ithaca, NY, Cornell University Press.

» Totten S.; Williams, P. \& R. Hitchcock (2002). “Confronting Genocide and Ethnocide of indigenous peoples; an interdisciplinary approach to definition, intervention, prevention and advocacy" en Hinton, A., Annihilating difference: the anthropology of genocide: 54-91. Berkeley/ Los Angeles/ London, University of California Press.

» Trouillot, M. (1995). Silencing de Past. Power and the Production of History. Boston, Beacon Press.

»Viñas, D. (1982). Indios, ejército y frontera. Buenos Aires, Siglo XXI.

»Wolfe, P. (2006). Settler colonialism and the elimination of the native. Journal of Genocide Research 8 (4): 387-409. 